\title{
La musivaria romana en época de Trajano
}

\author{
Guadalupe López MONTEAGUdo \\ CSIC
}

Con el advenimiento de Trajano al poder se inaugura una de las etapas más florecientes de la historia de Roma, no solo militar, sino también cultural, ya que durante su reinado (98-117 d.C.) se acometieron obras de gran envergadura que proporcionaron gran esplendor tanto a la capital del Imperio, como a las ciudades provinciales ${ }^{1}$.

Los pavimentos musivos no son ajenos a este esplendor de diecinueve años - que es el tiempo que dura el reinado de Trajano-, ya que es precisamente en esta época cuando se produce un cambio en la tradición musivaria en blanco y negro, que evoluciona hacia el color y los temas figurados, fenómenos artísticos que cristalizarán plenamente en época de Hadriano ${ }^{2}$. Los mosaicos se utilizan tanto en edificios públicos, como privados, adornan los suelos y las paredes de las casas, termas y tumbas, cubren piscinas, fuentes y ninfeos. En época de Trajano la técnica y el gusto por el mosaico tiene ya una larga andadura desde su creación el siglo IX a.C. (palacios de Tell-Ahmar en Siria) y su especial relevancia en época helenística (mosaicos de Grecia y Egipto). Se conocen las diferentes técnicas y usos del opus musivum, por lo que las innovaciones y las características de la musivaria trajanea van a concretarse más en el gusto por el color y por los temas figurados, en especial los mitológicos. La época de Trajano constituye, pues, el inicio del desarrollo del mosaico que, a partir de este momento, va a alcanzar su plenitud en el transcurso del siglo II y en el III, con el triunfo del llamado "estilo florido" todavía en blanco y negro, que hace su aparición en el reinado de Hadriano, y sobre todo con el predominio del color y de las grandes composiciones figuradas, evolucionando hasta las creaciones tardías de épocas posteriores.

Ciertamente, cuando faltan elementos de cronología absoluta, no es fácil delimitar con exactitud la fecha de un mosaico por criterios exclusivamente iconográficos o estilísticos, ya que en la musivaria las modas y los estilos perduran durante un tiempo que no tiene por qué coincidir exactamente con los años del reinado de un emperador, sino que pueden adscribirse a periodos de tiempo más amplios y, por este motivo, a veces se fechan de manera más o menos aproximada en época de los antoninos, o en época de los se-

1 Blazouez Martinez, J.M., Trajano, Madrid 2003.

2 Dunbabin, K.M.D., Mosaics of the Greek and Roman World, Cambridge 1999. 
veros, o por lo que ahora nos atañe en el primer tercio o en la-primera mitad del siglo II, sin poderse especificar con certeza absoluta si fueron realizados en época de Trajano o de Hadriano. Sí puede, sin embargo, afirmarse que a fines del siglo I y en la primera mitad del II existe una continuidad de la tradición helenística y un predominio del influjo itálico en la musivaria de Occidente, y que a partir de esta época, y sobre todo en el III, se produce ya un cambio en favor de los modelos norteafricanos y orientales.

En el Oriente, la musivaria de época de Trajano se inscribe en la tradición helenística tanto del mosaico bícromo, a veces trícromo, de decoración geométrica y ornamental, como los de Arsameia, cuanto en el mosaico helenistico polícromo de emblemata o pseudo-emblemata, es decir, de paneles figurados ilusionistas inspirados en modelos pictóricos e insertados en un cuadro geométrico, corriente en la que se encuadran los mosaicos más antiguos de Antioquía descubiertos en las casas destruídas por el terremoto del 113 d. C $^{3}$. Del triclinium de la Casa del Atrio procede un pavimento enteramente policromo, compuesto por cinco emblemata en forma de T, rodeados en tres de sus lados por una composición geométrica formada por una red de rombos (Fig. 1). La originalidad de este pavimento reside en que fué concebido en su totalidad como un conjunto realizado in situ y no los emblemata en un taller y luego insertados en un cuadro geométrico, como es habitual en época helenística. Los temas están sacados del repertorio mitológico tradicional bien conocido por la cerámica griega y las pinturas pompeyanas: Juicio de Paris, concurso de bebida entre Heracles y Dionisos, personajes del thiasos báquico, Afrodita y Adonis, y aunque en su composición el pavimento refleja modelos originarios de Roma, en otros aspectos, como su total policromía y su carácter pictórico, sigue las tradiciones helenísticas. El panel central, conservado en el Museo del Louvre, con la representación del Juicio de Paris (Fig. 2), enmarcado por una orla de roleos de vid con pájaros e insectos y dos cabezas humanas, está realizado con una técnica casi de vermiculatum, y con una rica gama de colores que incluye el empleo de teselas de vidrio en azul y verde para los detalles ${ }^{4}$.

En otras casas de la misma época uno de los pavimentos está decorado con la escena de Heracles niño estrangulando a las serpientes, mientras que otros muestran personajes itifálicos y ojo apotropaico ${ }^{5}$. El mosaico figurado polícromo de la parte oriental del Imperio se mantendrá siempre fiel a la tradición helenística y a ello ha de contribuir no solo la herencia del ideal clásico sino también la categoría social de los propietarios, pertenecientes a las élites cultivadas imbuidas de cultura griega.

3 BALTY, J., "La mosaïque au Prôche-Orient I. Des origins à la Tétrarchie», ANRW II.12.2, 1981, 347429; ID., Mosaïques antiques du Prôche-Orient. Chronologie, iconographie, interprétation, Besançon 1995.

4 LeVI, D., Antioch Mosaic Pavement, Princeton 1947, 6, 15-35, pl. I-V, XCIII-XCIV, CXLIla, CXLVCXLVIII. La reconstrucción virtual del pavimento en KONDOLEON, C., "Mosaics of Antioch", en Kondoleon, C. (et al.), Antioch. The lost ancient city, Princeton 2001, pp. 66-71, fig. p. 62.

5 LEVI, D., Antioch Mosaic Pavement, Princeton 1947, 28-34, pl. IV y XCIII. 


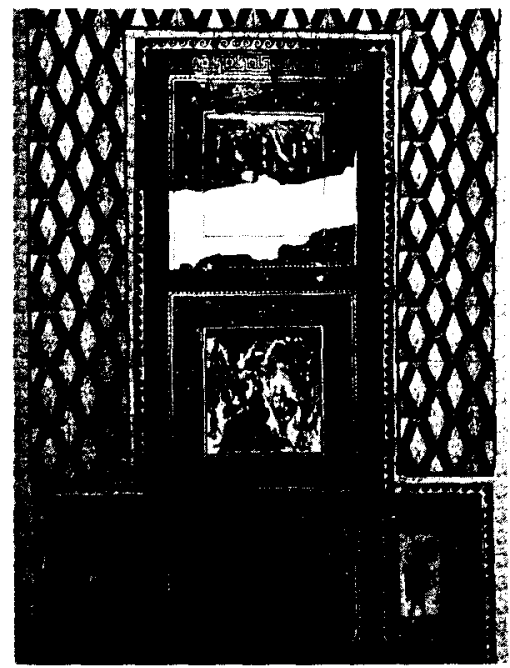

Figura 1.Antioquia, Atrium house. Reconstrucción de C. Kondoleon.

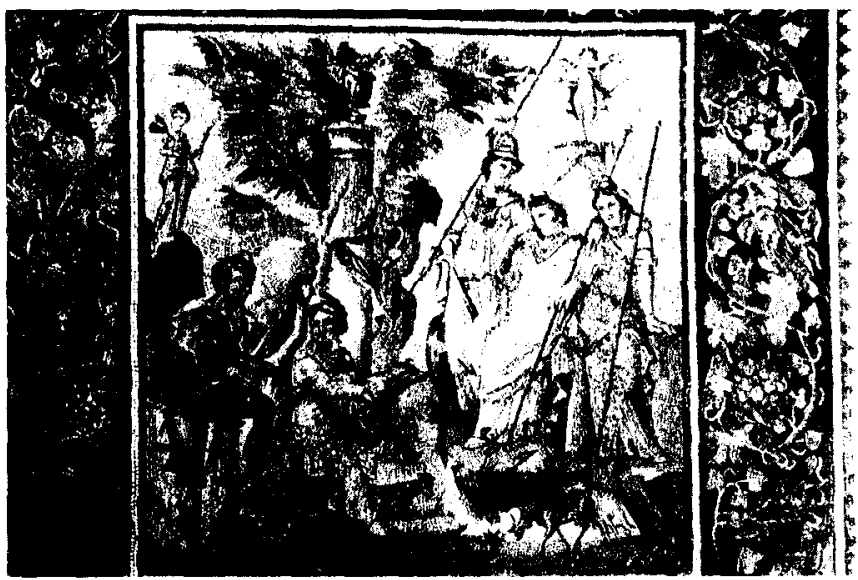

Figura 2. Antioquia, Atrium house. Mosaico del Juicio de Paris. Museo del Louvre.

Por lo que se refiere a los temas geométricos de los pavimentos de época de Trajano, aunque polícromos, tienen paralelos en el repertorio del mosaico geométrico en blanco y negro de Occidente: sogueado de dos o tres cabos, postas, meandros, dientes de sierra, círculos secantes, cubos en perspectiva, estrellas de cuatro puntas formadas por el juego de losanges, triángulos y cuadrados, nudos de Salomón, etc. Los motivos vegetales, como guirnaldas de flores y frutos, con animales y máscaras, o tallos de acanto, recuerdan a algunas pinturas pompeyanas contemporáneas muy impregnadas todavía del helenismo. Sin embargo, la principal diferencia con la musivaria de Occidente estriba en la pobreza del repertorio geométrico y en el empleo secundario que de los temas 
geométricos se hace en el Oriente, simplemente como marco para los emblemas figurados, en contraposición al mosaico romano de Occidente, en donde la riqueza y complejidad de las composiciones geométricas tienen valor por si mismas, de forma que, a veces, cuando en ellas se inserta un emblema, éste tiene la apariencia de un cuadro subordinado dentro del conjunto.

En Grecia el mosaico continúa en esta época en la línea del mosaico helenístico, es decir, es preferentemente polícromo, y solo esporádicamente se documentan ejemplares en blanco y negro, como el mosaico de guijarros de Thasos, decorado con una crátera, erotes y delfines, el mosaico de tema marino de Leucadia o el de Patras en el que se asocian delfines en blanco y negro y un panel polícromo ${ }^{6}$. La supervivencia de la tradición helenística se aprecia en los mosaicos polícromos de época trajanea descubiertos en una villa de Corinto; uno de ellos consta de tres paneles decorados con escenas nilóticas, pájaros y frutos, bordeados por una greca de meandros tridimensionales, y dos orlas de roleos de vid, motivos todos ellos que remontan a prototipos helenísticos (Figs. 3-4) 7 .

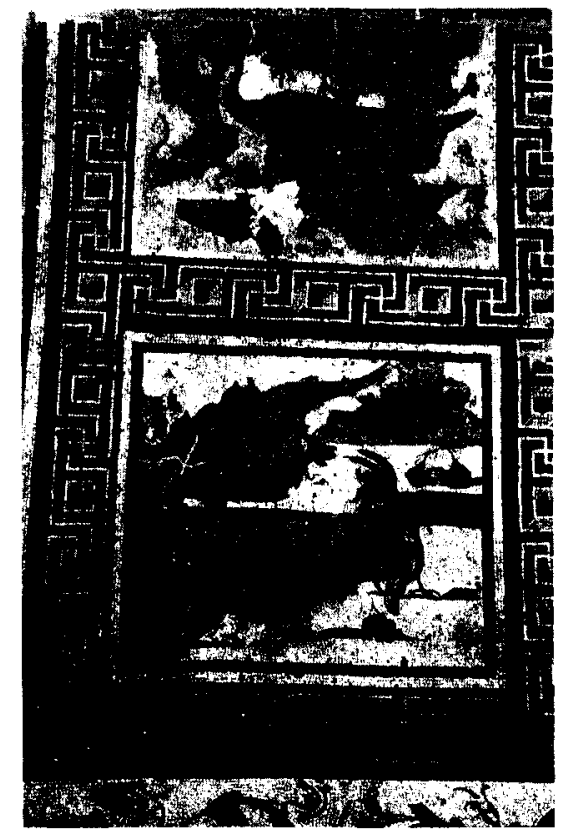

Figura 3. Corinto, villa romana. Museo Arqueológico de Corinto. Foto de la A.

"Bruneau, Ph., "Tendances de la mosaïque en Grèce à l'époque impériale", ANRW II.12.2, 1981, 320-346.

7 MtLleR, S.G., “A mosaic floor from a Roman villa at Anaploga”, Hesperia 41, 1972, 332-354, pl. 65-73. 


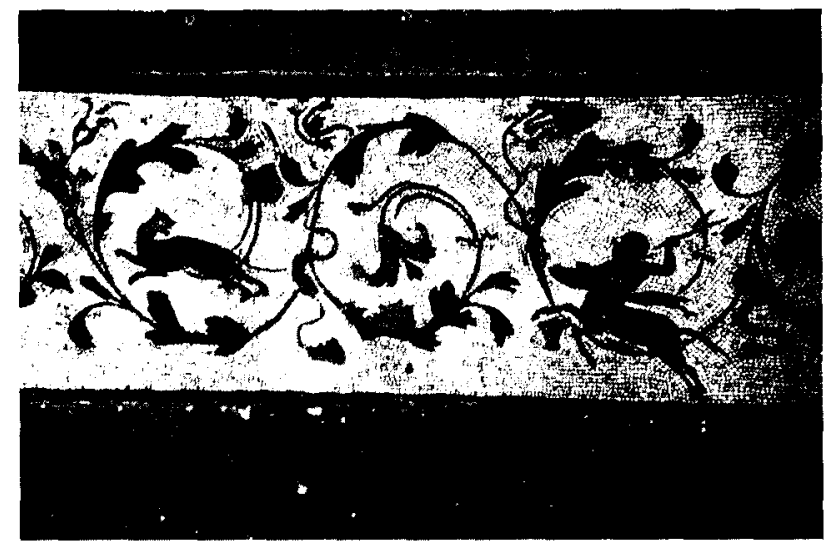

Figura 4. Corinto, villa romana. Detalle de la orla. Museo arqueológico de Corinto. Foto de la A.

Al mismo tiempo, el influjo itálico se deja sentir en las proximidades de Corinto, en el mosaico en blanco y negro de Isthmia, con escenas marinas en los dos rectángulos centrales (Fig. 5), estando el resto de la superficie dividida en cuadrados con decoración geométrica ${ }^{8}$. Otros mosaicos emparentados estrechamente con los diseños blanco y negros itálicos, pero que introducen ya el uso moderado del color, sobre todo del rojo, son los descubiertos en las Termas Kladeos de Olimpia, construídas hacia el año 100 d.C. A esta misma época pueden adscribirse los mosaicos de Philippi con el borde de murallas, muy lejos de la tradición helenística y, por el contrario, íntimamente conectados con los prototipos itálicos (Figs. 6-7) ${ }^{9}$. Esta marcada influencia de la metrópolis, que se manifiesta de manera especial en las termas y en lugares de fuerte presencia romana o itálica, como las colonias de Patras y Corinto, probablemente puede explicarse por la llegada de artistas o de modelos desde Italia, com o sugiere K.M.D. Dunbabin ${ }^{10}$.

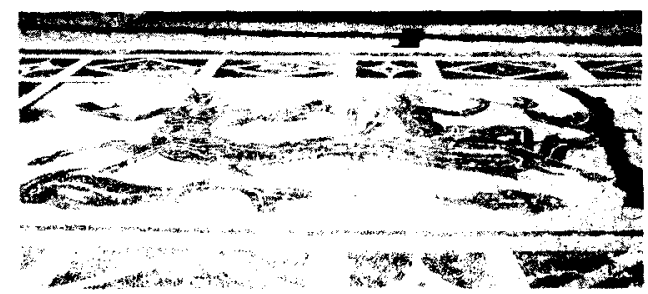

Figura 5. Isthmia, Termas. In situ. Foto de la A

\footnotetext{
8 PACKARD, P., "A monochrome mosaic at Isthmia", Hesperia 49, 1980, 326-346, pl. 97-101.

9 Collart, P., Philippes, ville de Macédoine, Paris 1937, 357-358, pl. LII-LIII.

10 Dunbabin, K.M.D., Mosaics of the Greek and Roman World, Cambridge 1999, 209-222.
} 


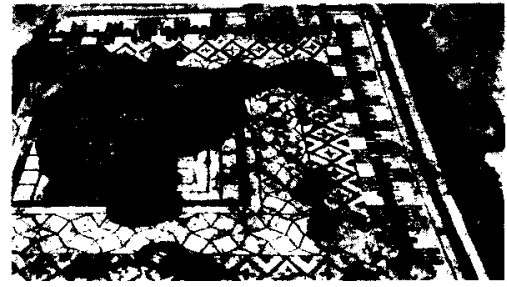

Figura 6. Philippi, mosaico de la orla de murallas. Desaparecido, Foto P. Collart

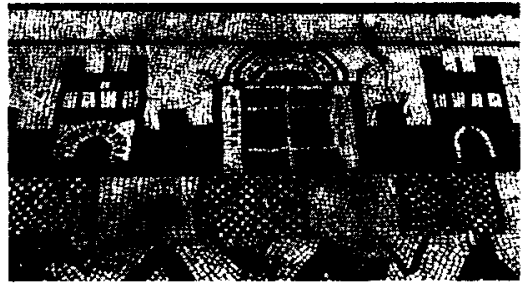

Figura 7. Phitippi, mosaico de orla de murallas. Detalle. Foto P. Collart.

Se conserva la fórmula tradicional del pseudo-emblema central y al mismo tiempo se crean composiciones no centradas, pero se mantienen los procedimientos gráficos y cromáticos y sobre todo la temática de época anterior, si bien no existe ninguna copia deliberada del mosaico helenístico. Este conservadurismo explica la ausencia o rareza de ciertos temas en la musivaria griega de época temprana, como los temas nilóticos tan ligados a la egiptomanía itálica, o las escenas de la vida rural o de circo que son excepcionales, y una predilección por los temas mitológicos que reflejan la fidelidad a la tradición helenística, aunque también hay un enriquecimiento del repertorio y del tratamiento de la temática anterior ${ }^{11}$. Una novedad respecto al mosaico helenístico es que desaparece la técnica del opus vermiculatum, que en Italia dura hasta el siglo II d.C., en favor del opus tessellatum de fondo blanco ${ }^{12}$.

En la Península itálica, los mosaicos del Mercado de Trajano en Roma y los de Ostia (Fig. 8) siguen en época de Trajano el gusto severo y sobrio tratados en bicromía, no por ello desprovisto de inventiva y de originalidad, de los tiempos flavios ${ }^{13}$. Estas mismas características se encuentran en mosaicos contemporáneos de otras zonas del Imperio ${ }^{14}$, en especial por la proximidad a la península itálica en Aquileya (Galia Cisalpina), Tréveris (Galia Belgica) y también en la provincia Narbonense (Valence), en donde el influjo itálico es tan fuerte que puede hablarse de talleres itinerantes llegados del N. de Italia; o ya en el N. de Africa en Cirenaica, Utica, Cartago o Cherchell. En Hispania los mismos motivos geométricos en blanco y negro, tratados

11 WAYWELL, S., "Roman Mosaics in Greece», AJA 83, 1979, 293-321.

12 Bfuneali, Ph., "Tendances de la mosaique en Grèce à l'époque impériale», ANRW II.12.2, 1981, 320-346.

13 BECATTI, G., "Alcune caratteristiche del mosaico bianco-nero in Italia", CMGR I, Paris 1965, 15-28; ID., "Alcune caratteristiche del mosaico policromo in Italia", CMGR II, Paris 1975, 173-179.

14 Darmon, J.P., "Les mosaïques en Occident I", ANRW II.12.2, 1981, 266-319. 
con gran elegancia y sobriedad, formando nidos de abeja, meandros de esvásticas, rosetas de triángulos curvilíneos, temas de laberinto, etc., se documentan en Ampurias, Badalona, Clunia, Marbella, Itálica o Mérida.

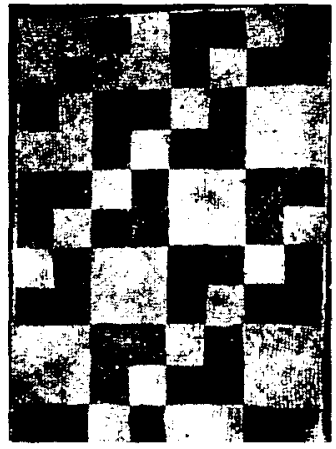

Figura 8. Ostia, Insula delle Volte dipinte. Foto G. Becatti.

Asimismo, las elegantes composiciones de estrellas de ocho losanges y octógonos adyacentes que determinan cuadrados, están ampliamente representadas en el repertorio musivo desde los dos primeros siglos de la Era, documentándose en Pompeya (Casa de los Amorini Dorati), Ostia (insula delle Muse y domus Fulminata), Aquileya, o villa de Este (Figs. 9-10) ${ }^{15}$. En Hispania este esquema conoce una gran difusión desde el siglo II, destacando los ejemplos de Ampurias, Clunia, Mérida, Itálica, Carmona, Córdoba y Marbella ${ }^{16}$.

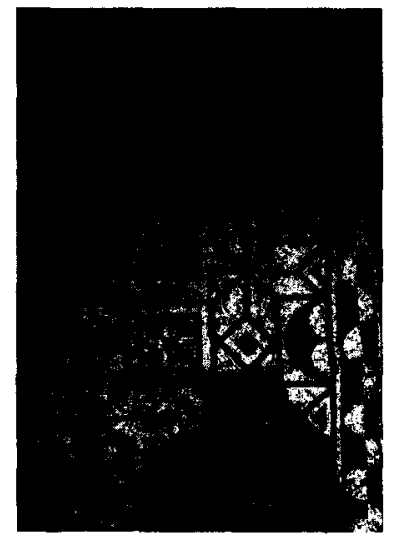

Figura 9. Ostia, Domus Fulminata. Foto G. Becatti.

15 BLAKE, E., "The Pavements of the Roman Buildings of the Republic and Early Empire", MAAR VIII, Roma 1930, 7-160; ID., "Roman Mosaics of the Second Century", MAAR XIII, Roma 1936, 67-214; BECATTI, G., Scavi di Ostia, IV, Roma 1961.

16 Recopilaciones en Bafral y ALTET, X., Les mosaïques romaines et médiévales de la Regio Laietana, Barcelona, 1978, 55-56; Blanco, A., Mosaicos romanos de Itálica, CMRE II, Madrid 1978, 18-19; BLAZoUEZ, J.M., Mosaicos romanos de Córdoba, Jaén y Málaga, CMRE III, Madrid 1981, 25; BLAZOUEZ, J.M., Ortego, T., Mosaicos romanos de Soria, CMRE VI, Madrid 1983, 54; López Monteagudo G. ET ALII, Mosaicos romanos de Burgos, CMRE XII, 1998, 56-60, $n^{\circ} 8$. 


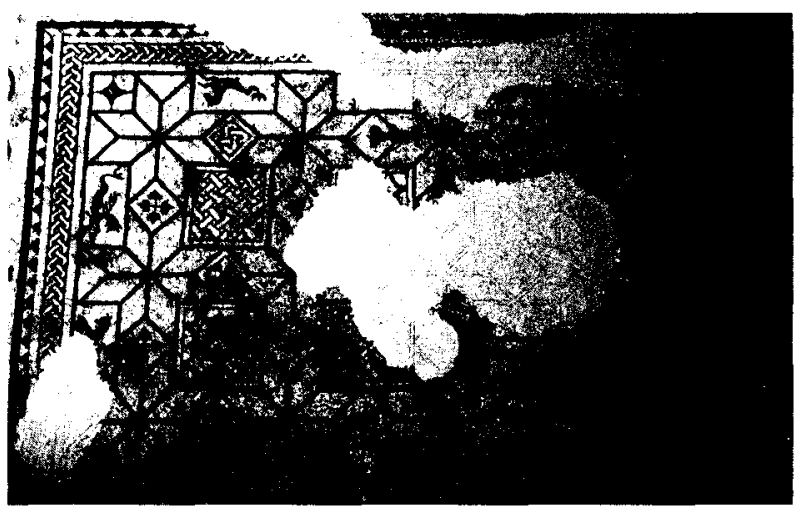

Figura 10. Este, Villa Albrizzi. Museo Arqueológico de Este. Foto de la A.

La composición de esquema a compás, formada por un círculo central, semicírculos laterales y cuartos de círculo en los ángulos, tiene una amplia distribución en la parte occidental del Imperio, hallándose su raíz en la Península itálica, en donde se documenta en Pompeya (Casa del Poeta Trágico), Ostia (insula delle pareti gialle) y Lucera (Figs. 11-12)17. El esquema se origina a partir de la decoración arquitectónica de bóvedas de techo, cuya estructura compartimentada pasa a la superficie plana del pavimento. El modelo itálico, junto a sus motivos decorativos más usuales, es adoptado por los talleres provinciales desde el siglo II d.C. En Hispania encuentra relativa acogida en ejemplos de gusto italianizante, que incluyen elementos geométricos, vegetales y de veneras (pavimentos de la casa $n$. $^{\circ}$ 1 de Clunia y de la Basílica de Uxama, con paralelos muy estrechos en un mosaico de Aquileya), y también figurados, como es el caso de los mosaicos de Seleucus y Anthus, en Mérida, la Medusa de Marbella, la Venus de La Quintilla, en Murcia, por citar solo unos ejemplos en los que se hace patente el enriquecimiento que el esquema original itálico sufre en Hispania a partir de los inicios del siglo Il con la introducción del empleo del color, de forma tímida al principio hasta alcanzar las composiciones enteramente polícromas del siglo II (mosaico de la Loba y los Gemelos de Alcolea de Córdoba, que incluye el color amarillo y las teselas de pasta vítrea, el Rapto de Ganímedes de Itálica o el Rapto de Europa de Ecija) y de épocas posteriores ${ }^{18}$.

17 BLAKE, E., "The Pavements of the Roman Buildings of the Republic and Early Empire", MAAR VIII, Roma 1930, pl. 22.4; ID., "Roman Mosaics of the Second Century", MAAR XIII, Roma 1936, pl. 33.1; BECAITI, G., Scavi di Ostia, IV, Roma 1961, tav. CCXXIV.

18 Fernandez Galiano, D., Mosaicos hispánicos de esquema a compás, Guadalajara 1980; BLAZQuez, J.M., Mosaicos romanos de Córdoba, Jaén y Málaga, CMRE III, 1981, 43 ss.; LoPEz MONTEAGUdo G. ET ALII, Mosaicos romanos de Burgos, CMRE XII, 1998, 62-65.; LoPEZ MONTEAGudO, G., Mosaicos hispanos de época de Trajano, en J.M. Blázquez (ed.), El Imperio de Trajano, Madrid, 2002, 55-87. 


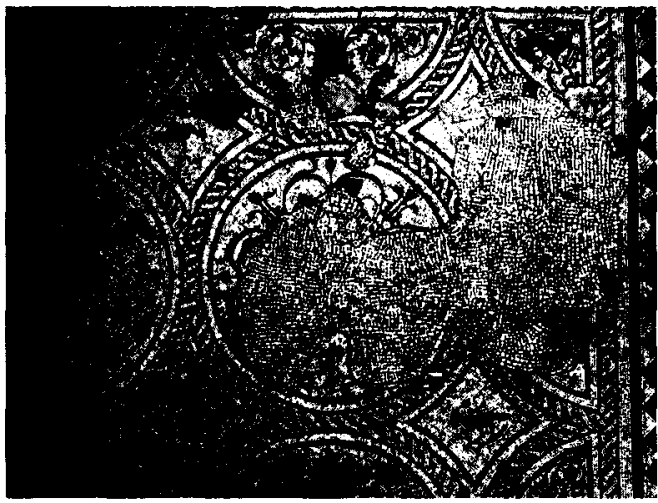

Figura 11. Ostia, Insula delle Pareti Gialle. Foto G. Becatti

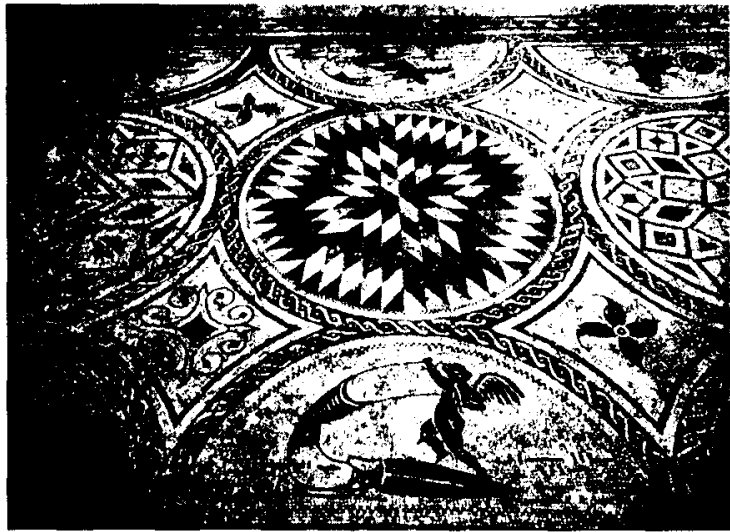

Figura 12. Lucera, mosaico de esquema a compás. Foto E. Blake.

La musivaria del $\mathrm{N}$. de Africa ofrece grandes diferencias entre regiones o provincias, de forma que no pueden aplicarse generalidades ${ }^{19}$. Así los pavimentos de la Tripolitania se distinguen como un grupo aparte caracterizado por la ausencia del "estilo florido" y en donde predomina el empleo de los emblemata destacando en una composición geométrica ${ }^{20}$. Una villa de la Tripolitania cuyos mosaicos se fechan, no sin gran controversia, entre finales del siglo I y la primera mitad del II, es la de Zliten. Los pavimentos geométricos de Zliten pertenecen al estilo llamado de «decoración múltiple», raro en el $\mathrm{N}$. de Africa; algunos incluyen combinaciones de cuadros realizados en opus tessellatum y opus sectile, como el famoso pavimento del friso decorado con escenas de anfiteatro en policromía, de gran importancia porque refleja con todo realismo los diferentes juegos y el equipo de los luchadores,

19 Dunbabin, K.M.D., The Mosaics of Roman North Africa, Oxford 1978.

20 Aurigemma, S., L'Italia in Africa. Tripolitania. I mosaici, Roma 1960. 
los condenados a las fieras y los músicos con sus instrumentos, como el órgano (Fig. 13) ${ }^{21}$. En esta época se ha datado un mosaico polícromo de volutas, realizado con la técnica del vermiculatum, que pavimentaba una pequeña habitación de forma más o menos circular. Del círculo central solo se ha conservado una guirnalda sostenida por bucráneos que delimita un espacio semicircular decorado con animales marinos. El resto de la superficie se halla ocupada por roleos de acanto, que salen de un gran tallo, y diversos animales, como pájaros, insectos y mamíferos, todo realizado con una gran finura y naturalismo que le aproxima a la tradición helenística, muy diferente del llamado «estilo florido" típico del N. de Africa ${ }^{22}$.

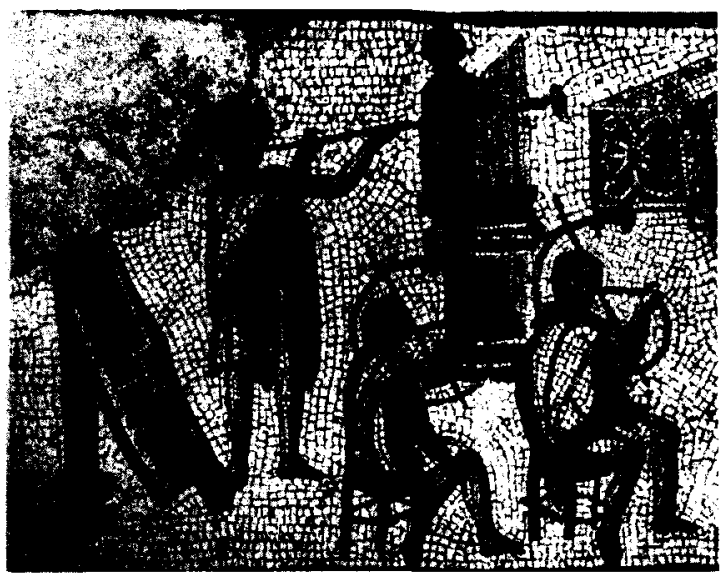

Figura 13. Zliten, detalle de la orla del mosaico de anfiteatro. Museo Arqueológico de Tripoli. Foto S. Aurigemma.

En la Proconsular la frecuencia de mosaicos con decoración geométrica en blanco y negro a comienzos el siglo II d.C. hace suponer la existencia de talleres locales establecidos en Utica, Thysdrus, Hadrumetum y Acholla, caracterizados por su austeridad y el uso restringido del color, lo que se ha dado en llamar "estilo severo". Muy pronto el diseño geométrico se vuelve polícromo y se le añaden elementos estilizados vegetales, dando lugar al primer estilo específicamente norteafricano conocido con el nombre de "estilo florido", cuyos antecedentes sin embargo se encuentran en los arabescos blancos y negros de la Península itálica ${ }^{23}$. De esta forma, las monótomas composiciones bícromas de círculos secantes o tangentes pierden su sobriedad y rigidez y se transforman en frescas coronas vegetalizadas, que van a caracterizar a la musivaria africana de

21 BLazouez, J.M. ET ALII, «Pavimentos africanos con espectáculos de toros. A propósito del mosaico de Silin (Tripolitania)", Ant. Afr. 26, 1990, 155-204.

22 Dunbabin, K.M.D., Mosaics of the Greek and Roman World, Cambridge 1999, 119-122.

23 PICARD, G. Ch., "Les débuts de l'école africaine de mosaïque», BAC 12-14, 1976-1978, 23-32; ID., "Un thème du style fleuri dans la mosaïque africaine", CMGR I, Paris 1965, 125-135. 
esta época y de las siguientes y en su evolución darán lugar a las ricas y polícromas guirnaldas que, incluso, se expandirán en época tardía a Italia e Hispania (Piazza Armerina, El Ramalete). En cuanto a las escenas figuradas, inspiradas en la mitología o en la vida diaria, se caracterizan por sus grandes dimensiones ya que los emblemata o pseudo-emblemata se adaptan a las superficies de las estancias que cubren, originando un gran tapiz decorativo y, en ocasiones, historiado.

Los primeros mosaicos norteafricanos pertenecientes a este nuevo estilo proceden de las llamadas Termas de Trajano en Acholla, en las que destaca el gran pavimento del frigidarium presidido por el Triunfo de Baco, que ofrece varias novedades ${ }^{24}$. La composición se halla formada por dos rectángulos principales y una zona central dividida por dos bandas diagonales que determinan paneles trapezoidales (Figs. 14-15). Como en el caso de las composiciones de "esquema a compás", también ésta parece reflejar una composición de bóveda, reforzada por los motivos decorativos en forma de "grutescos" medio humanos medio vegetales, animales heráldicos, candelabros, motivos estos últimos que se documentan en la Domus Aurea sobre todo y también en Pompeya y Herculano ${ }^{25}$. En cuanto a los elementos figurados, hay que destacar dos peculiaridades de este mosaico, que son la asociación y contaminación de los temas báquicos y marinos (presencia de nereidas y tritones en un thiasos báquico), y la sustitución de los felinos del carro de Baco por centauros (Fig. 16) ${ }^{26}$. Sin embargo, ninguna de ellas es exclusiva de Acholla ya que la primera se documenta también en otros lugares del N. de Africa, como Thysdrus, Bir Chana, Cherchell, Hadrumetum, Hippo Regius, Sfax, Themetra, Thuburbo Maius y Utica, así como en los mosaicos griegos del Triunfo de Baco de Dion y Corinto, y en Hispania constituye una de las características más llamativas de algunos mosaicos contemporáneos de la Bética (Itálica, Cádiz), donde los tritones se realizan con unos rasgos faciales muy próximos a los de los sátiros del cortejo dionisiaco, que se subrayan con los típicos atributos báquicos como son los cuernos, el pedum y la antorcha. Esta asociación y contaminación iconográfica entre el thiasos marino y el dionisiaco es un hecho generalizado y de larga perduración en el mundo romano, sobre todo en la Península itálica, como puede comprobarse en el mosaico de las Termas de Neptuno o en el de la domus dei dioscuri, en Ostia ${ }^{27}$.

\footnotetext{
24 PICARD, G., "Les thermes du Thiase marin à Acholla", Ant.Afr. 2, 1968, 95-151; GozLAN, S., La Maison d Triumphe de Neptuno à Acholla (Botria-Tunisie), 1992.

25 PICARD, G.Ch., “De la Maison d'Or de Néron aux thermes d'Acholla», MonPiot 63, 1980, 63-104.

26 Cf. Lopez Monteagudo, G., «Sobre una particular iconografia del Triunfo de Baco en dos mosaicos romanos de la Bética», Anales de Arqueología Cordobesa 9, 1998, 179 ss., con toda la bibliografía.

27 TORRES, M., “lconografía marina", en Mosaicos Romanos. Estudios sobre iconografia. Actas del Homenaje in Memoriam de Alberto Balil, Guadalajara 1990, 107-134
} 


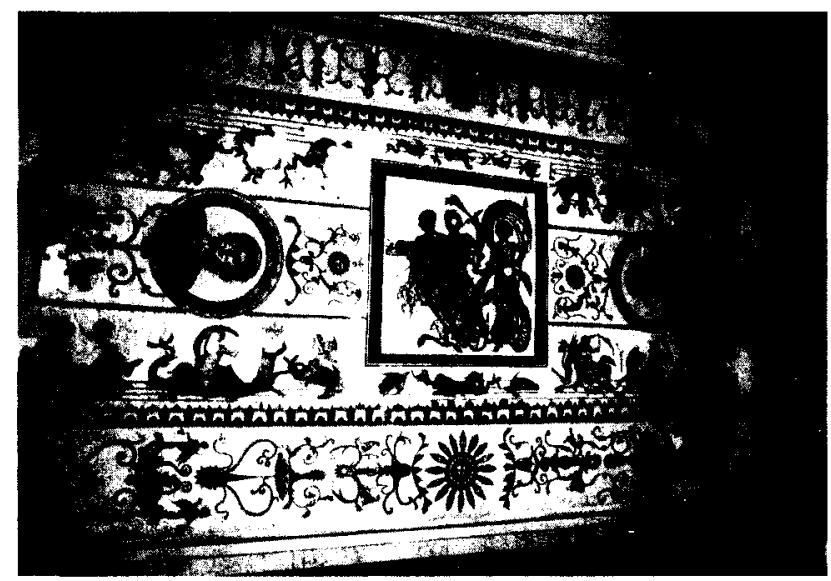

Figura 14. Acho!la, Termas de Trajano. Museo del Bardo. Foto de la A.

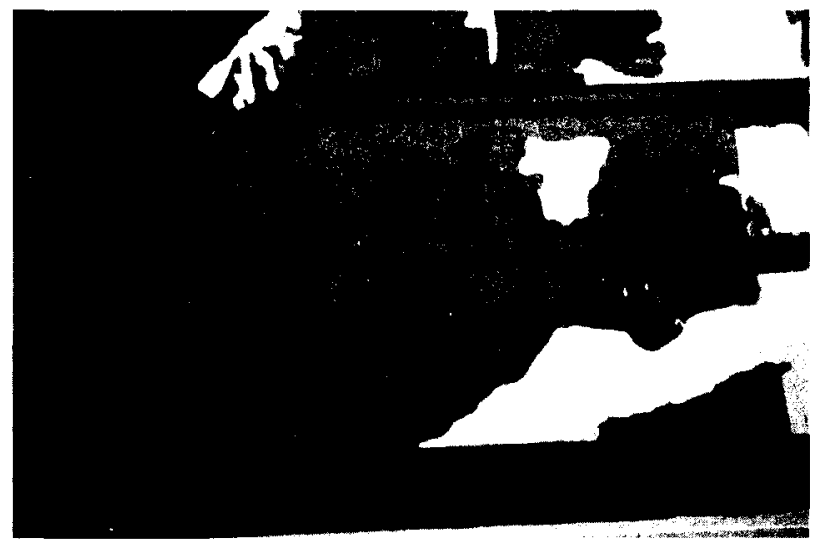

Figura 15. Acholla, Termas de Trajano. Museo del Bardo. Foto de la A.

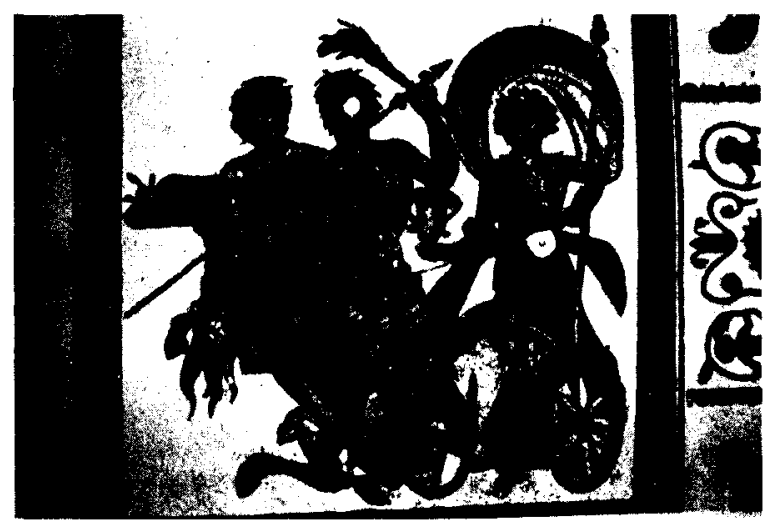

Figura 16. Acholla, Termas de Trajano. Museo del Bardo. Foto de la A. 
La sustitución de los felinos por los centauros en los mosaico norteafricanos de Acholla y Thysdrus se documenta, asimismo, tanto en Occidente como en Oriente, con una amplia cronología, en los mosaicos hispanos del Triunfo báquico de Ecija y Alcolea de Córdoba, en el mosaico itálico en blanco y negro de Tenuta de Fiorano y ya en el Oriente en los pavimentos del thiasos báquico de Gerasa, Sepphoris, Nea Paphos y Sheikh Zouède ${ }^{28}$. Esta iconografía del carro de Dionisos tirado por centauros, que gozó de un gran favor en la primera mitad del siglo II tanto en la musivaria como en los sarcófagos, se habría inspirado según L. Foucher en el grupo firmado por Aristeas y Papias, procedente de la escuela de Afrodisias de Caria, que mostraba ya a dos centauros, uno viejo y otro joven, sin olvidar los de la villa hadrianea de Tívoli y la descripción hecha por Luciano (Zeux. 4 ss.) de una pintura de Zeuxis que representaba la theleia hippocentauros, $y$, por supuesto; la relación del tema con las tendencias de la época que asimilaban, sobre todo a partir de la guerra pártica, a Trajano con el dios evergeta, dominador del Oriente, guerrero victorioso contra la barbarie, representada por esos seres brutales semi humanos, semi animales, que son los centauros, y propagador de la civilización y de la virtus romana que dispensa la Felicitas $^{29}$.

La evolución y desarrollo del mosaico blanco y negro en la Península lbérica se relaciona con el mismo fenómeno seguido en Italia en los siglos I y II d.C., especialmente por lo que a los mosaicos de Ostia se refiere, apareciendo el mismo tipo de mosaico figurado en blanco y negro en Hispania durante el siglo $\mathrm{II}^{30}$. Esto confirma el carácter netamente itálico de este primer periodo de producción, revelando el gusto de las clases dirigentes hispanas por el arte de la capital, si bien la interpretación que se hace en Hispania del esquema itálico presenta variantes, de forma que a veces se encuentran verdaderas copias realizadas por artistas itálicos y en otras ocasiones la falta de habilidad para ejecutar los efectos de la perspectiva denota la mano de un artesano local. En todo caso, puede decirse que los pavimentos en blanco y negro, sobre todo los geométricos, son muy abundantes en toda la geografía hispana durante los dos primeros siglos de la era.

El mosaico bícromo alcanza una gran difusión en Cataluña, valle del Ebro y litoral levantino, con predominio al principio de esquemas geométricos de gran complejidad, introduciéndose en la primera mitad del siglo II d.C. motivos figurados ${ }^{31}$, como las orlas de murallas - Caldes de Montbui

28 Lopez Monteagudo, G., "Sobre una particular iconografía del Triunfo de Baco en dos mosaicos romanos de la Bética", Anales de Arqueología Cordobesa 9, 1998, 179 ss., con toda la bibliografía.

29 Foucher, L., Le char de Dionysos, CMGR II, Paris 1975, 55 ss.; F. TuRCAN, Les sarcophages romaines à représentations dionysiaques, Paris 1966, 505 ss.

30 Ramallo Asensio, S., "Talleres y escuelas musivas en la Peninsula lbérica», en Mosaicos Romanos. Estudios sobre iconografía. Actas del Homenaje in Memoriam de Alberto Balil, Guadaiajara 1990, $135 \mathrm{ss.}$

31 BARRAL I ALTET, X., Les mosaïques romaines et médiévales de la Regio Laietana, Barcelona, 1978, 43 y 148; BlazQuez, J.M., MezQuiriz, M.A., Mosaicos romanos de Navarra, CMRE VII, 1985, 54-56, nüms. 34 y 35 , láms. 33 y 34 . 
(Fig. 17) y Pamplona - frecuentes en la Península itálica en el siglo I y II, donde se documentan en Pompeya y en Ostia en sus dos modalidades, blanco sobre negro y negro sobre blanco (Palazzo Imperiale y Termas dei Cisiari), en el siglo II, o los tritones afrontados -termas de San Miguel en Barcelona (Fig. 18) - estos últimos inspirados en modelos de las termas pompeyanas o en los repertorios ostienses de thiasos marino, muy en boga a partir de la época de Trajano y de los Antoninos (termas de Fiorano, cerca de Via Appia y Museo de Ancona) $)^{32}$.

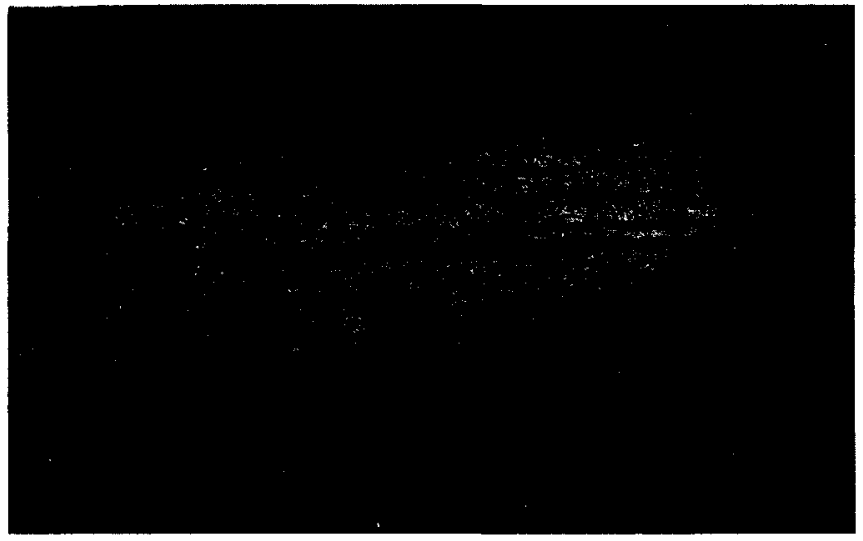

Figura 17. Caldes de Montbui, Termas. In situ. Foto de la A.

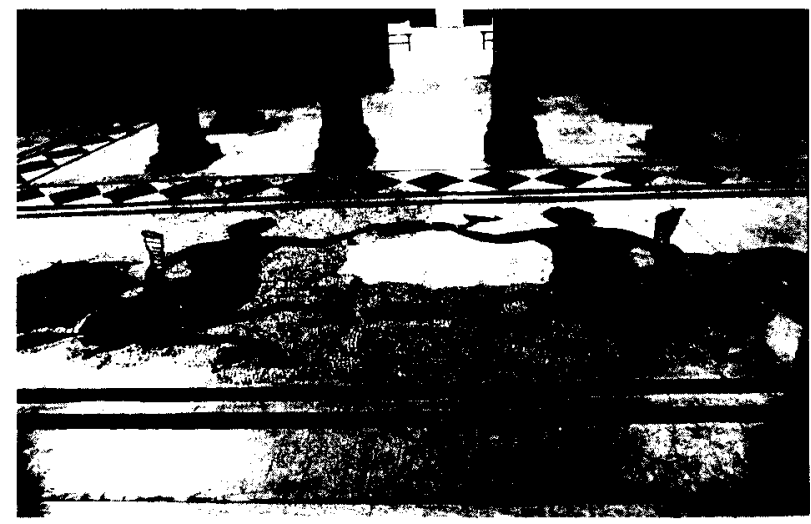

Figura 18. Barcino, Termas de San Miguel. Museo Arqueológico de Barcelona. Foto X. Barral i Altet.

Las representaciones de divinidades y personajes marinos - Neptuno, Océanos, tritones, nereidas, hipocampos - se encuentran entre los prime-

32 BLAKE, E., "The Pavements of the Roman Buildings of the Republic and Early Empire", MAAR VIII, Roma 1930, pl. 26 y 27; BECATt।, G., Scavi di Ostia, IV, Roma 1961, tavv. XVI y CVII. 
ros mosaicos de temática mitológica que se realizan en Hispania -BarceIona (Fig. 19), Elche, Mérida, Itálica, Cádiz - y se hallan íntimamente ligadas, tanto por los rasgos iconográficos de las figuras como por su composición, a las producciones itálicas (Termas de Neptuno, en Ostia), reflejando fielmente los temas y las modas imperantes en la metrópolis ${ }^{33}$. Pero también, ya desde los primeros momentos se deja ver el gusto hispano por el color, que no desbanca, como ocurre en Italia, la pervivencia de la moda bícroma aún en mosaicos del siglo III.

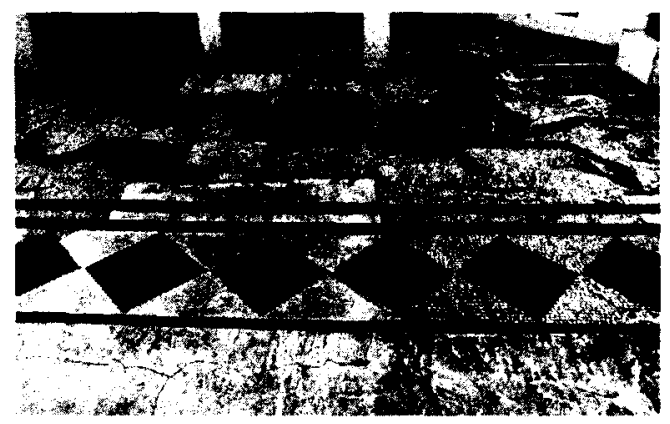

Figura 19. Barcino, Termas de San Miguel. Museo Arqueológico de Barcelona.

Foto X. Barral i Altet.

En el litoral levantino destacan los mosaicos de Sagunto, que muestran el estadio final en la evolución de los talleres bicromos hacia nuevas formas polícromas, tras la paulatina incorporación de cuadros figurados en una composición geométrica en blanco y negro - mosaico del Castigo de Dirce (Fig. 20) -, particularidad que también se documenta en algunos pavimentos de Mérida - mosaico del Rapto de Europa - y de la Bética pavimentos de Baco de Itálica, de la Medusa de Itálica, Carmona y Córdoba, y de Pegaso de Córdoba - y cuyos prototipos remontan a veces a ambientes extraitálicos siguiendo la tradición helenística ${ }^{34}$. El perdido mosaico saguntino de Baco niño cabalgando la pantera, con una serie de cenefas geométricas en torno a un cuadro en el que se figuran erotes vendimiadores, que recogen el fruto de los tallos que brotan de las cráteras dispuestas en los ángulos (Fig. 21), señala la introducción de nuevos temas figurados en los talleres bícromos, adaptados a nuevos espacios arquitectónicos ${ }^{35}$.

33 TORRES CARRo, M., "lconografia marina", en Mosaicos Romanos. Estudios sobre iconografia. Actas del Homenaje in Memoriam de Alber to Balil, Guadalajara 1990, 107 ss.

34 Cf. Lopez MONTEAGUdo, G., “Los mosaicos mitológicos hispano-romanos en el contexto de la cultura mediterránea en la Antigüedad", Historia Antigua, Moscú (en prensa), con toda la bibliografía.

35 BALIL, A., El mosaico de Dionysos hallado en Sagunto, SA. 53, 1979. 


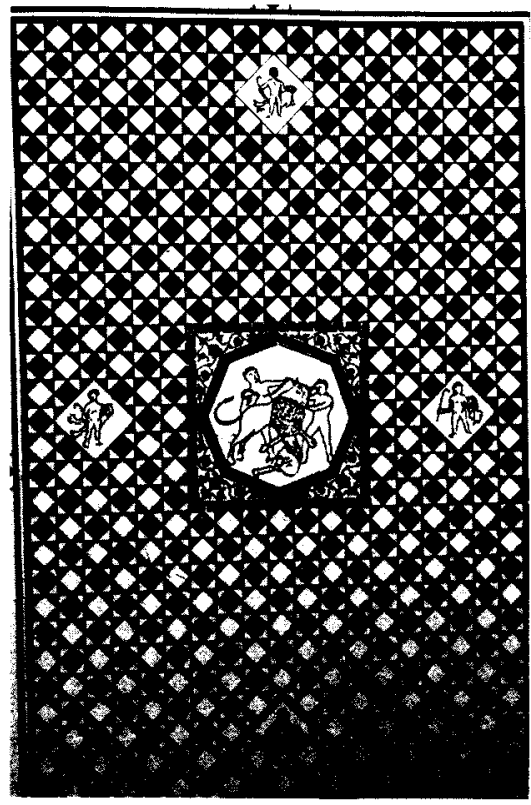

Figura 20. Sagunto, mosaico del Castigo de Dirce. Museo Arqueológico de Sagunto. Según A. Balil

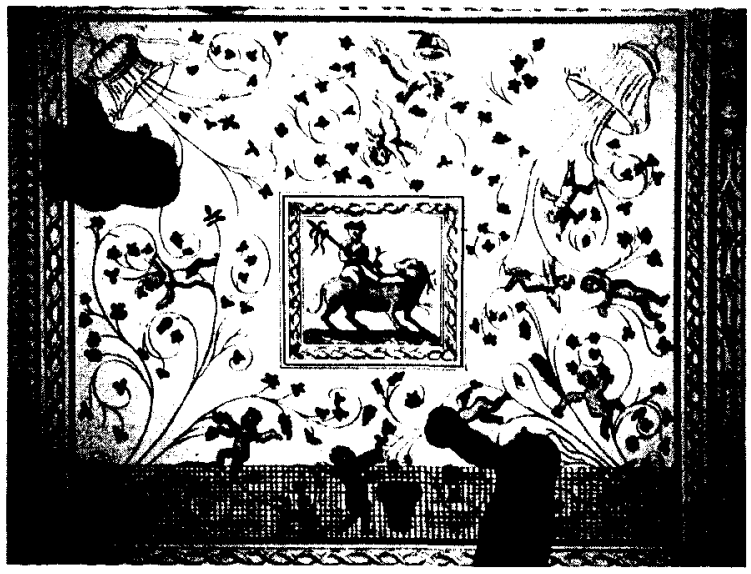

Figura 21. Elche, mosaico de Baco niño. Desaparecido. Dibujo en la Real Academia de la Historia.

Una de las ciudades más importantes de la Bética fue Corduba, donde el opus tessellatum, alcanzó su momento de mayor esplendor, demanda y difusión precisamente tras la transformación de la ciudad en Colonia Patricia, coincidiendo con el proceso de monumentalización que comienza con Augusto y alcanza su punto culminante entre los siglos I y II d.C. Ello, sin embargo, no significa que los pavimentos provengan de edificios públicos, 
sino que, por el contrario, decoran fundamentalmente ámbitos de carácter privado, como triclinios, oecus, exedras o cubicula de las domus ${ }^{36}$.

El estudio de los pavimentos cordobeses ha permitido identificar no solo la existencia de talleres y la utilización de los mismos cartones, sino también el establecimiento de relaciones entre mosaicos del área urbana de Corduba y otros procedentes de su entorno o de otros lugares de la Bética. Baste recordar los mosaicos de thiasos marino procedentes de Córdoba capital y del Cortijo del Alcaide (Fig. 22), o los esquemas compositivos en los que el emblema central se integra en una composición de semiestrellas tangentes, que forman hexágonos oblongos, de los mosaicos de la Medusa de Córdoba (Fig. 23), Itálica y Carmona, y de Baco de la Casa de los Pájaros en Itálica, sin olvidar el emblema polícromo de Pegaso (Fig. 24) inserto en una composición ortogonal de círculos secantes que determinan flores cuatripétalas en blanco y negro con introducción de teselas rojas, esquema muy frecuente en Corduba capital y provincia entre la primera mitad del siglo II d.C. y finales del III d.C. ${ }^{37}$ Otro pavimento de la Colonia Patricia, cuyo esquema geométrico se basa en una composición ortogonal de cuadrados recargados con nudos de Salomón o flores cuatripétalas y rombos adyacentes, mantiene estrechos paralelos con el esquema geométrico empleado en dos mosaicos de la casa de Mitra en Cabra y en otro procedente de la villa cordobesa de EI Ruedo ${ }^{38}$.

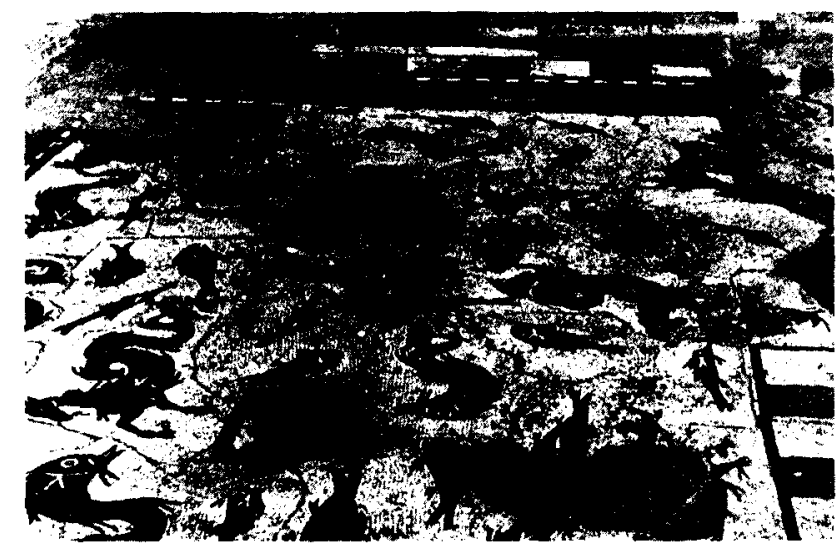

Figura 22. Córdoba, Cortijo del Alcaide. Museo Arqueológico de Córdoba. Foto J.M. Blázquez.

\footnotetext{
36 Moreno Gonzalez, M.F., Aproximación al estudio de la decoración musivaria en Colonia Patricia Corduba, Memoria de Licenciatura leida en la Universidad de Córdoba en 1995, publicación en microficha n. 134 del Servicio de Publicaciones de la Universidad de Córdoba, 1996; ID., "Nuevas aportaciones al estudio del mosaico romano en Corduba Coionia Patricia", AEspA. 70, 1997, 101 ss.

37 BLAzQuez, J.M., Mosaicos romanos de Córdoba, Jaén y Málaga, CMRE III, 1981, 19-21, 25-26, 33$35,48-49,50$ y 102 , núms. $4,9,15,17,28$ y 31 D, figs. $9-10,17,19$ y 32 , láms. $3-6,11,37-38$ y 83.

38 HIDALgo Prieto, R., "Mosaicos con decoración geométrica y vegetal de la villa romana de El Ruedo (Almedinilla, Córdoba)", Anales de Arqueologia Cordobesa 2, 1991, 333-334, lám. V.
} 


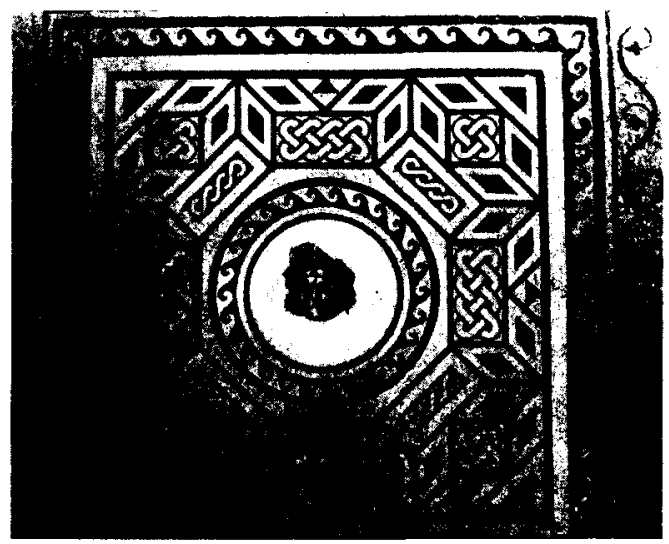

Figura 23. Córdoba. Mosaico de Medusa. Museo Arqueológico de Córdoba. Foto de la A.

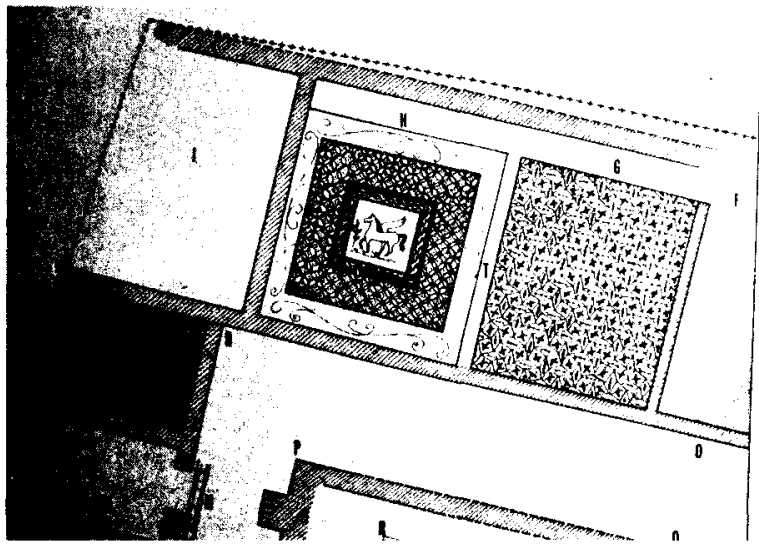

Figura 24. Córdoba, casa romana. Según A. García y Bellido.

En Itálica, la ciudad hispana más paradigmática del reinado de Trajano ya que es su ciudad natal, máximo ejemplo del triunfo de la romanización en una provincia y uno de los lugares en donde el auge de la vida urbana se produjo de forma temprana, los mosaicos son el resultado de unos talleres con cartones muy elaborados, en los que predomina ya el uso del color, aunque a veces sea en tonalidades reducidas. Un claro exponente de esta ambigüedad lo constituye el mosaico de Neptuno, en el que se combina la tradición bícroma, empleada en todo el repertorio de figuras marinas - tritones, delfines, peces y otros monstruos marinos - que rodean al dios, tratado en policromía, que ocupa el centro de la composición, sobre el carro tirado por caballos marinos (Fig. 25) ${ }^{39}$. Esta composición unitaria, que sigue modelos ostienses (mosaicos de las Termas de Neptuno, dei Cisiari o de Bu-

39 BLANCO, A., Luzon, J.M., El mosaico de Neptuno en Itálica, Sevilla 1974. 
ticosus), sobre todo para las figuras de los tritones y de Neptuno, este último también con paralelos muy próximos en los mosaicos de Risaro y Palermo, está rodeada por una orla de tradición helenística con escenas nilóticas, también muy frecuente en los ámbitos ostienses, pero tratada dentro de la más pura tradición musiva italicense ${ }^{40}$.

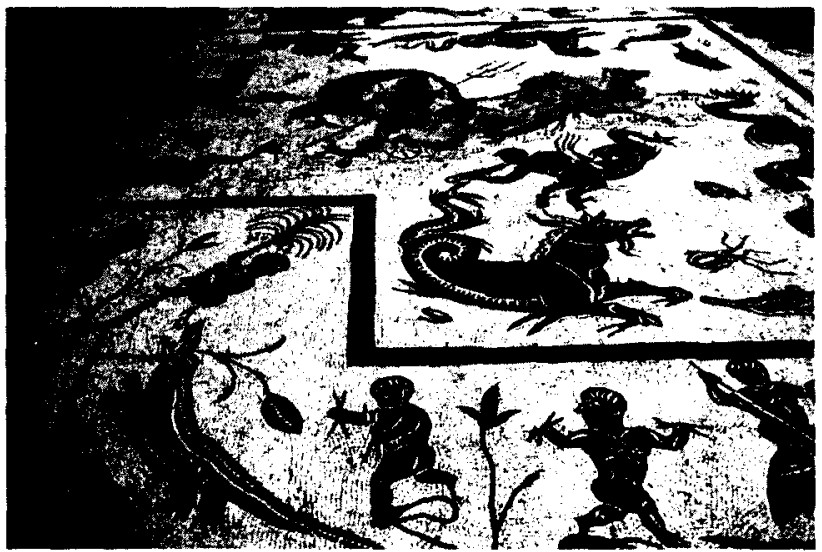

Figura 25. Itálica, Casa de Neptuno. In situ. Foto A. Blanco, J.M. Luzón

Como en el caso de Córdoba y de ltálica, los pavimentos de Ecija, la antigua colonia Augusta Firma Astigi, destacan por la originalidad de sus esquemas compositivos y por el tratamiento iconográfico de los temas figurados, que los ponen en conexión con otros lugares próximos de la Bética, en especial Cabra, Córdoba e Itálica, revelando la existencia de un posible taller ubicado en la propia Astigi o en alguna de las zonas próximas ${ }^{41}$. Las excavaciones llevadas a cabo en Ecija han puesto de manifiesto una superposición de pavimentos y muros, que revelan la existencia de dos fases constructivas con un profundo cambio a fines del siglo II y comienzos del III respecto a la etapa anterior que puede fecharse del siglo I d.C. a la segunda mitad del II.

El siglo ll es la época de más auge en la economía de la colonia, a juzgar por los hallazgos arqueológicos -en especial ánforas olearias - y epigráficos, que testimonian en esta época el mayor momento de producción y exportación del aceite astigitano, auge que se refleja en los restos arquitectónicos del foro y de dos complejos termales descubiertos en el subsuelo de la ciudad actual. A esta época se pueden adscribir algunos de los pavimentos astigitanos de mejor calidad técnica y artística, pertenecientes a una rica casa romana, en la que se atestiguan tres niveles de habitación que van de fines del siglo I al IV, construída con una buena edilicia y pavimenta-

40 BECATTI, G., «Alcune caratteristiche del mosaico bianco-nero in Italia", CMGR I, Paris 1965, 15 ss.

41 Lopez Monteagudo, G., "Los mosaicos romanos de Ecija (Sevilla). Particularidades iconográficas y estilisticas", VIII CIMA, Lausanne 2001, 130-146. 
da con ocho mosaicos, entre los que destacan tres escenas figuradas policromas de carácter mitológico: el Rapto de Europa, que ocupa el círculo central de un mosaico de esquema a compás, una escena de la lliada y sobre todo el mosaico báquico presidido por la figura de Baco niño sobre pantera (Fig. 26), más próximo al opus vermiculatum que al tessellatum. La composición iconográfica de este último le convierte en un unicum en la musivaria romana, además de su calidad técnica y artística, a la que contribuye el empleo de teselas de pequeño tamaño en las figuras y la rica y variada utilización del color con teselas de pasta vítrea, que proporcionan los matices adecuados, de forma que más parece una obra pictórica que musiva.

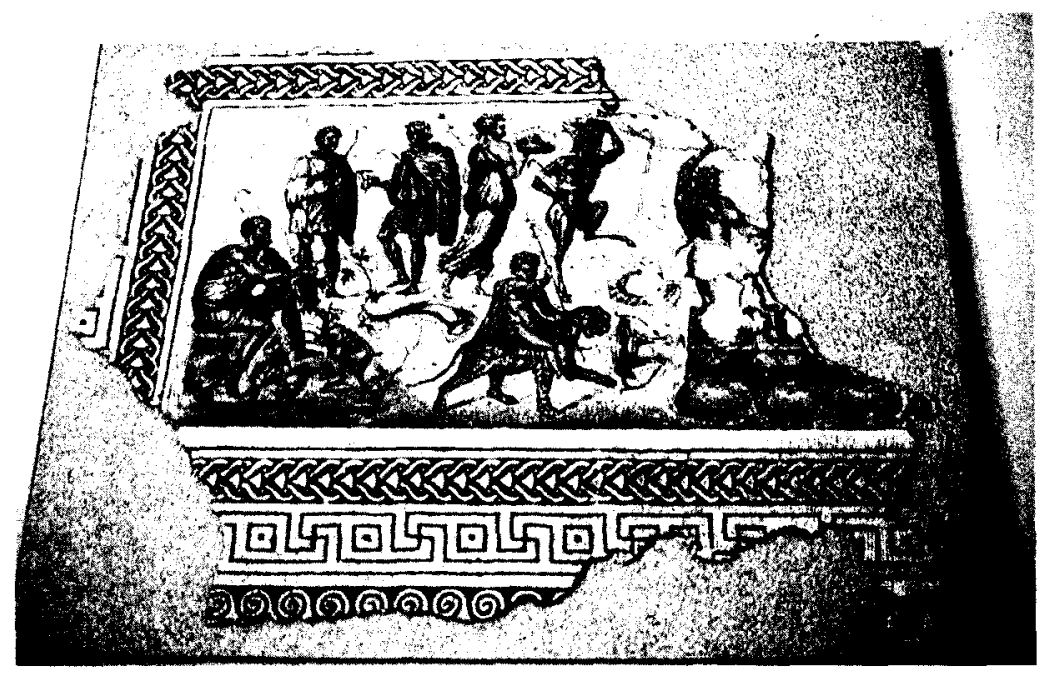

Figura 26. Ecija, Casa Romana. Museo Arqueológico de Ecija. Foto de la A.

En Lusitania, los talleres que operan en la capital, Augusta Emerita, desde finales del siglo I d.C., desarrollan la técnica del blanco y negro en composiciones geométricas y florales de origen itálico ${ }^{42}$. Ejemplos de esta corriente artística son los mosaicos de la llamada Casa de la Torre del Agua, que muestran un fondo de roleos con hojas de hiedra (Fig. 27); la pavimentación blanca y negra, sin nota alguna de otro color, de la Casa-basílica a la que se superpone, respetando una gran parte de los suelos preexistentes, una posterior en blanco, negro, amarillo y rojo, cuyos motivos decorativos, siempre geométricos, se encuentran en Pompeya y Ostia; los mosaicos geométricos de la Casa del Mitreo (Fig. 28); y el mosaico de Baritto (Fig. 29), tal vez procedente de una tumba, ofrece dos cráteras agallonadas con cruz gamada en el cuello, entre dos delfines y otros dos peces, tal vez besugos, y las inscripciones FELIX, BARITTO COLONIAE (servus) y BONIS, quizás haciendo referencia a Bonis eventis.

42 Blanco Frejeiro, A., Mosaicos romanos de Mérida, CMRE I, Madrid 1978, 28-29, 45-47, núms. 5 , $40,41,46-50$, láms.6-7, 75, 81-83. 


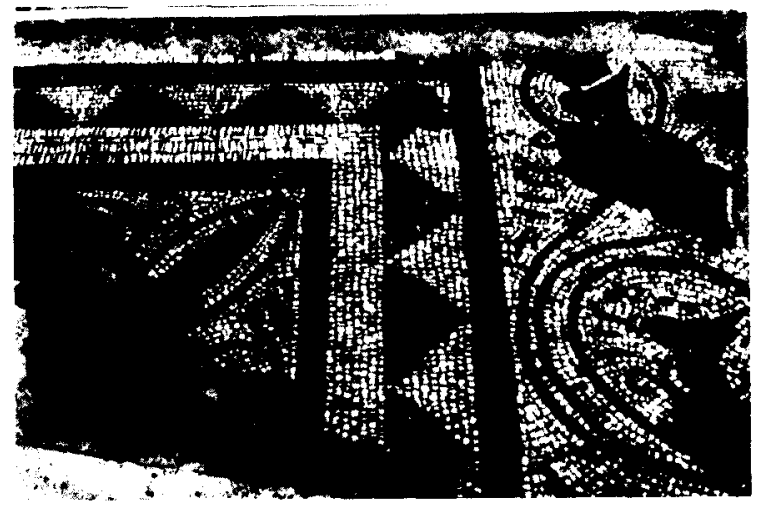

Figura 27. Mérida, Casa de la Torre del Agua. Foto A. Blanco.

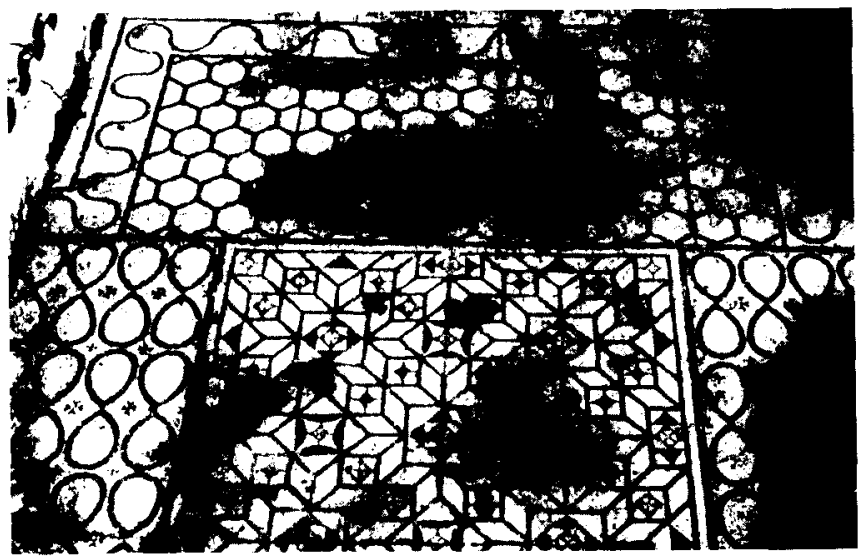

Figura 28. Mérida, Casa del Mitreo. Foto A. Blanco.

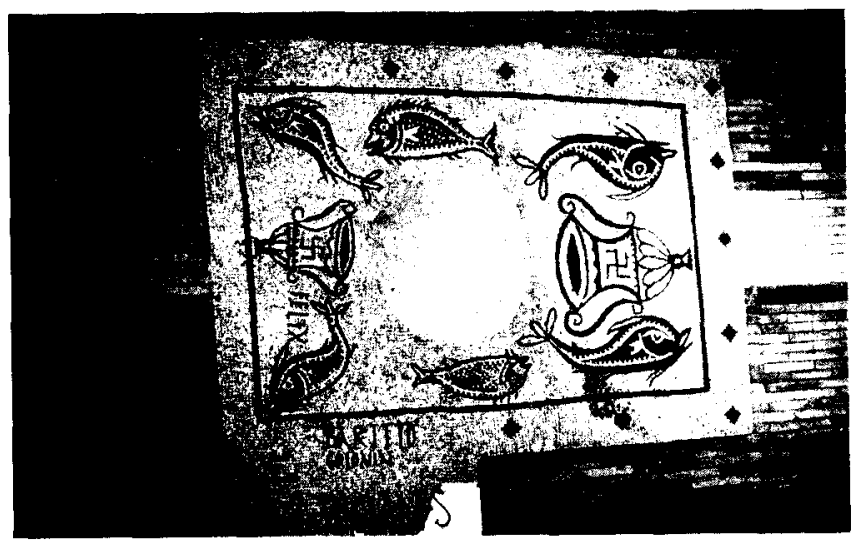

Figura 29. Mérida, mosaico de Baritto. Museo de Arte Romano de Mérida. Foto Museo. 
En algunos casos las composiciones geométricas bícromas alternan con pequeños cuadros polícromos figurados de procedencia oriental, en una simbiosis que combina los esquemas bícromos de tradición itálica y los cuadros pictóricos polícromos de tradición helenística, del que no faltan ejemplos en Hispania (mosaico del Sacrificio de Ifigenia de Ampurias) ${ }^{43}$. A esta modalidad pertenecen los mosaicos emeritenses de Seleucus y Anthus (Fig. 30), una composición de esquema a compás con paralelos temáticos y estilísticos en Ostia, pero realizada por unos artesanos de filiación oriental, según denotan sus nombres escritos en una cartela en forma de tabula ansata, que introducen tímidamente el color y el simbolismo propios del Oriente en la decoración de la orla; y el del Rapto de Europa, cuya superficie se halla dividida en dos compartimentos bícromos (Fig. 31). El umbral, de forma rectangular, está decorado con un damero de escuadras contrapuestas con dos pequeños cuadrados entre los extremos de sus brazos, esquema que aparece por vez primera en los mercados de Trajano y que se repite en la insula delle volte dipinte, en Ostia. El resto forma una composición ortogonal de estrellas de cuatro puntas tangentes en negro, recargadas con un cuadrado inscrito por los vértices, formando rombos horizontales y verticales en blanco que dejan entrever octógonos secantes y tangentes, en el que se inserta el pequeño emblema polícromo. El tipo iconográfico del Rapto de Europa de Mérida, que figura el principio de la travesía marina, remonta al segundo estilo pompeyano y no se generaliza antes de comienzos el siglo II d.C., repitiéndose en emblemas musivos itálicos de comienzos del siglo II d.C., como los de Tívoli y Detskoje Sselo, procedente este último de Roma, en monedas Sidón y de Creta, de época de Trajano, y sobre todo en lucernas del tipo VII B de Deneuve, procedentes del N. de Africa ${ }^{44}$.

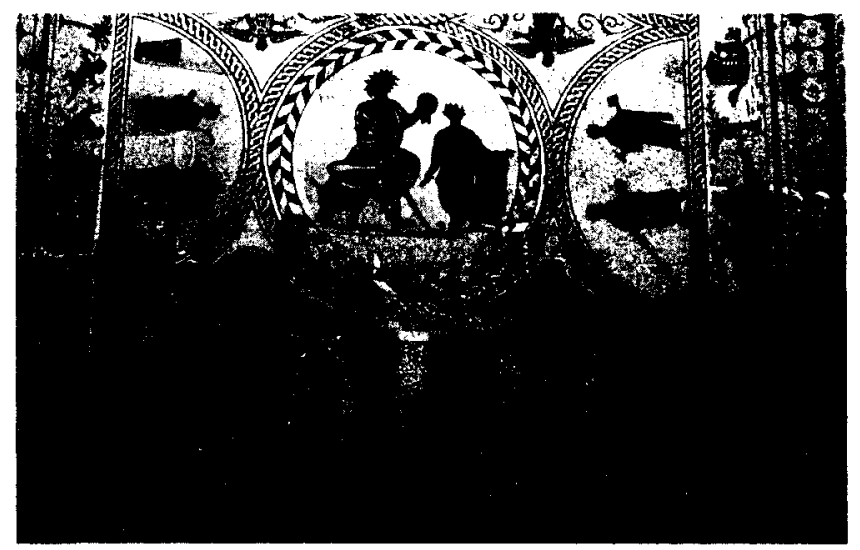

Figura 30. Mérida, mosaico de Seleucus y Anthus. Museo de Arte Romano de Mérida. Foto Museo.

43 IBID., 28, 30-32, núms. 4 y 9 , láms. 5, 12-20 y 99;

44 Lopez Monieagudo, G., San Nicolas Pedpaz, M.P., “El mito de Europa en los mosaicos hispano-romanos. Análisis iconográfico e interpretativo", Espacio, tiempo y Forma, Serie II, Historia Antigua 8, 1995, 381 ss. 


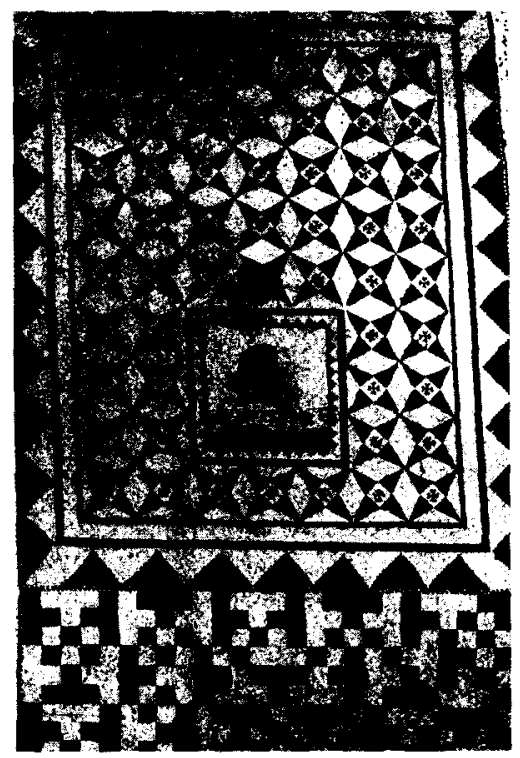

Figura 31. Mérida, mosaico del Rapto de Europa. Museo de Arte Romano de Mérida. Foto Museo.

En el interior de la Peninsula Ibérica el taller de Clunia-Uxama muestra una serie de composiciones geométricas sencillas, ligadas a la tradición del mosaico blanco y negro, donde de forma tímida se van introduciendo unas pinceladas de color ${ }^{45}$. Son excepcionales los mosaicos rigurosamente bicromos, ya que incluso en composiciones de rancio abolengo bitonal, como son los dameros conocidos en Italia desde época flavia, se combina el rosa, el violeta y el ocre-amarillo en oposición con el negro. Este taller, que actúa en Clunia en las Grandes Termas públicas, en las Pequeñas Termas del Foro y en las Casas $n .{ }^{\circ} 1$ y 3 , así como en la llamada «Basílica» de Uxama (Figs. 32-34), muestra junto a las tradicionales composiciones de esquema a compás y estrellas de ocho losanges, una trama con reticulado de bandas que, como único motivo ornamental, introduce pequeñas florecillas en el centro de los cuadrados resultantes, antecedente inmediato de las composiciones más tardias con cuadriculado de bandas y empleo del blanco y negro. La aparente policromia de los pavimentos clunienses no es una faceta nueva en la musivaria hispana altoimperial. Sin embargo, su reducido empleo y la imagen de tricromia que ofrecen, revelan la obra de unos artesanos que se mantienen fieles a la tradición bícroma de los patronos itálicos, pero que al mismo tiempo incorporan desde sus comienzos el color, al igual que sucede en Itálica y en Mérida y, fuera de Hispania, en Antioquía.

45 Fernandez Galiano, D., Mosaicos hispánicos de esquema a compás, Guadalajara 1980; Lopez Mon. TEAGUDO, G. ET ALII, Mosaicos romanos de Burgos, CMRE XII, Madrid 1998, 49 ss. 


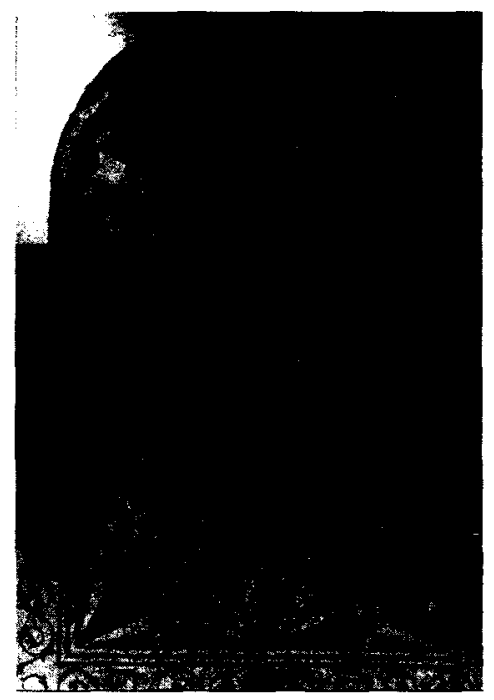

Figura 32. Clunia, Casa romana núm. 1. Museo Arqueológico Nacional. Foto M.A.N.

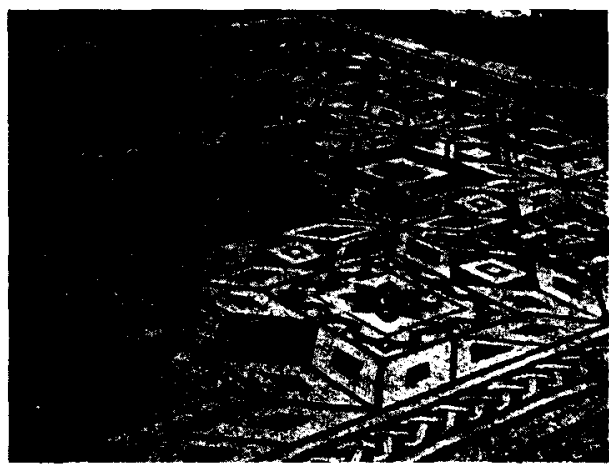

Figura 33. Clunia, Casa romana núm. 1. In situ. Foto R. Navarro.

Uno de los aspectos más discutidos en la musivaria hispana, ha sido el del intercambio de influencias que pueden estructurarse en tres grandes corrientes, cuyos origenes se encuentran en Italia, Galia y N. de Africa, a las que ha de sumarse la de procedencia oriental. En términos generales puede decirse que las aportaciones traídas por los artesanos venidos del exterior, algunos de cuyos nombres se han conservado, debieron causar algún impacto en los talleres locales creando en algunos casos un intento de imitación o acercamiento a los nuevos conceptos artísticos. La misma introducción gradual del color sobre el tradicional mosaico blanco y negro parece indicar una evolución desde dentro como consecuencia del estímulo exterior, a lo que hay que sumar las influencias africanas, sobre todo en las orlas polícromas, y las orientales que se manifiestan de forma especial en el empleo de determinados temas de carácter mitológico centrados sobre 


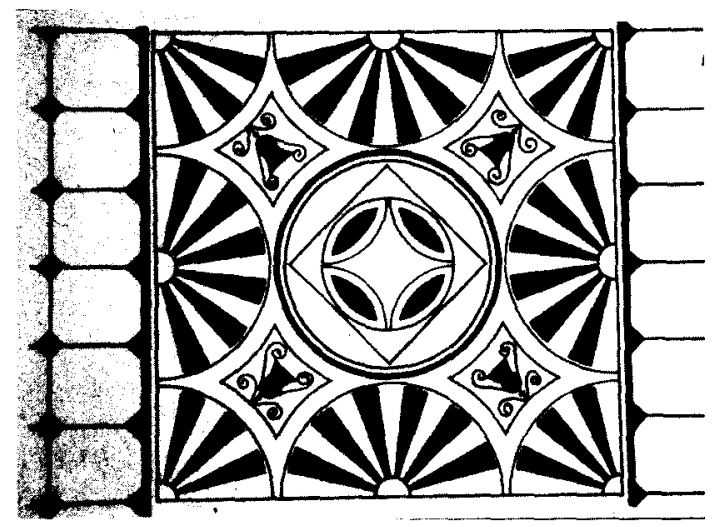

Figura 34. Uxama, Basilica. Según D. Fernández-Galiano.

composiciones bícromas. Varias son las causas que provocan esa influencia del exterior en la actividad artística de Hispania: el prestigio de las ciudades, la riqueza de la vida urbana y las necesidades de mano de obra para la actividad edilicia de Trajano, los servicios y la asistencia de las aristocracias locales favorecen el proceso inmigratorio. Por otro lado, la promoción de los hispanos y en especial de los paisanos del emperador a puestos de responsabilidad en el imperio, junto a personajes procedentes del oriente romano, produce el cosmopolitismo que se detecta sobre todo en la ciudad de ltálica y el afianzamiento de la tradicional movilidad de los italicenses a través de los lazos familiares con gentes de otras provincias ${ }^{46}$.

Para concluir, el corto periodo de tiempo del reinado de Trajano, tan solo dicinueve años, es un espacio cronológico demasiado escaso como para poder establecer unos límites claros en las corrientes artísticas que se detectan en los pavimentos musivos, por lo que es difícil hablar de la musivaria trajanea como una corriente artística con características propias. Sin embargo, la época trajanea es importante en el desarrollo de la musivaria romana en general, ya que supone un periodo de innovaciones en el que se recoge la tradición artística anterior - la bicromía, el empleo del color y el ilusionismo pictórico - y se comienzan a combinar ambas técnicas artísticas que evolucionarán por el camino de la policromía a lo largo del siglo II hasta cristalizar en los magníficos mosaicos polícromos de los siglos II y III. La época trajanea constituye, pues, el germen de lo que va a ser la musivaria romana en el reinado de Hadriano y sus sucesores, la cantera de la que van a surgir nuevos estilos, diferentes formas de concebir las superficies y sobre todo el predominio de los cuadros figurados, sacados de la tradición mitológica greco-helenística y de la vida diaria, que, a través de distintas adaptaciones, combinaciones y transformación van a perdurar en los siglos posteriores.

46 Lopez Monteagudo, G., "Mosaicos hispanos de época de Trajano", en J.M. Blázquez (ed.), El Imperio de Trajano, Madrid, 2002, 55-87. 